\title{
Universalidad de los derechos humanos y filosofía china clásica
}

\section{Introducción}

¿Qué significa tratar la cuestión de la validez universal de los Derechos Humanos desde una perspectiva filosófica, y no, por ejemplo, desde una perspectiva jurídica o política? Significa, entre otras cosas, que ni el derecho positivo ni las convenciones políticas internacionales (incluyendo la Declaración de los Derechos Humanos aprobada por la ONU), por sí solos, no son suficientes y ni siquiera apropiados para fundamentar una validez universal de los Derechos Humanos, pues, como es sabido, el derecho positivo puede ser inmoral. Además, no se sigue que, por el mero hecho de que algo exista, sea moralmente justo o que deba seguir existiendo. Y, por último, vale afirmar: La validez universal de una norma moral no depende de si se la cumple en una determinada cultura, o si está formulada en ella. Es evidente, además que determinadas tradiciones culturales facilitan la realización de los Derechos Humanos, mientras que otras la dificultan.

En el fondo, la cuestión filosófica de los Derechos Humanos es un viejo problema filosófico que se puede entender así:

1. ¿Qué debemos hacer?

2. ¿Hay normas morales (o éticas) universalmente validas que nos lo digan?

3. En caso positivo, ¿cuáles? Si no, ¿por qué no?

4. $Y$, en el caso positivo, ¿cómo se puede fundar la validez universal de las normas aducidas?

De la complejidad de los problemas mencionados voy a destacar un tema importante y fructífero: La cuestión de la validez de la norma de la inviolabilidad de la dignidad humana. La constitución alemana tiene un 
artículo que reza: "La dignidad del ser humano es inviolable". En la Declaración Universal de los Derechos Humanos se habla de una dignidad inherente a todos los seres humanos. Además, se dice que todos los seres humanos son iguales en dignidad por nacimiento. Estos son ejemplos de una institucionalización jurídica o casi jurídica del derecho al respeto de la dignidad humana. Una institucionalización semejante puede ser poco justificada o no plausible en el sentido que se le opongan argumentos válidos o ejemplos falsificantes. ¿Qué podemos aducir a favor de la convicción "La dignidad del ser humano es inviolable" y su institucionalización?

Algunos argumentos conocidos son:

1. La dignidad humana es expresión de un mandamiento divino o incluso de una especie de institución divina.

2. Se fundamenta en el derecho natural.

3. Es resultado de una reflexión pragmática ex-post-et-e-consequentibus, $y$, asimismo, de la concepción de que un mero acuerdo convencional sobre la institucionalización jurídica de la norma de la inviolabilidad ofrece la mejor protección para el ser humano (el individuo) ante la tortura, la humillación y la explotación, y de que una protección óptima es deseable.

No me parece que los intentos de fundamentación religioso-teológicos o de derecho natural sean válidos, ni tạmpoco convincentes, ni mucho menos capaces de un consenso universal. En su contra se habla de irracionalidad fundamental de muchos principios religiosos -que son tenidos por los creyentes como salvíficos- o la incompatibilidad de principios fundamentales de las distintas religiones. En el caso de la fundamentación en base al derecho natural tenemos, a mi parecer, que enfrentar con dificultades epistemológicas insuperables. Está en especial el peligro de una falacia naturalista. Una justificación pragmática de la norma de la inviolabilidad como institución jurídica me parece por el contrario posible. Evidentemente, ella tendría también un carácter filosófico o por lo menos rasgos filosóficos significativos.

La sencilla $-y$, de alguna manera, muy popular - pregunta: “ $¿ \mathrm{Ha}$ formulado también la filosofía china clásica nociones normativas de dignidad humana inviolable?, es irrelevante desde un punto de vista sistemático. Además, una cuestión semejante se sitúa frecuentemente en el ambiente de la problemática de los llamados valores no occidentales y en especial, los asiáticos. Algunos que creen haber identificado un "valor asiático específico" piensan que han mostrado con ello que determinadas normas, caracterizadas como "occidentales" no tienen validez universal. Junto a las confusiones sistemáticas está también en juego aquí la ignorancia: Las culturas 
no occidentales, o bien no se conocen, o se conocen de manera insuficiente. A esto se añade frecuentemente una actitud sorprendentemente acrítica: Se cree simplemente lo que cuentan misioneros culturales (como Daisetz Suzuki) y políticos interesados en su poder (como Lee Kuan Yew).

En cambio, tiene realmente sentido ocuparse de la filosofía china clásica, si a) se puede esperar que con ello se van a encontrar importantes filosofemas y argumentos que la "propia" tradición no ofrece, y b) si se puede elevar el nivel argumentativo, p.e., en la discusión en torno a conceptos válidos y convincentes sobre la dignidad humana.

Así se formulan especialmente en los libros Menzius y Xunzi (cuyos contenidos se pueden remontar a los siglos IV y III antes de Cristo) conceptos de la dignidad humana. De acuerdo a Menzius, se trata de una potencialidad innata (una disposición) en cada ser humano, en tanto que ser humano, de dignidad humana y - como potencialidad - incluso se trata de una dignidad inalienable. Según Menzius, ningún ser humano pierde la posibilidad de comportarse de tal manera que puede ser respetado por los otros como portador de un alto valor depositado en él. Quien - como, por ejemplo, un criminal violento y brutal - no cultiva la potencialidad que le es inherente, enajena su derecho a la estimación correspondiente, comparable con alguien que pierde sus derechos civiles de honra. En su fundamentación de la doctrina de que a cada ser humano le es inherente dignidad como potencialidad, sigue el libro Menzius un planteamiento naturalista y se expone de esta manera a objeciones parecidas a las que se puede hacer a la teoría del derecho natural.

El libro Xunzi ve en la dignidad humana un producto de cultivo moral (o ético), y en especial de cultivo de sí mismo, que merece admiración y respeto, porque representa el mejor aporte a una vida humana y pacífica de todos los seres humanos. Con ello desarrollo una teoría empírico-histórica de la dignidad humana que se puede resumir así: A partir de todo lo que sabemos por la experiencia (lo que observamos) se puede decir que la naturaleza humana es mala en el sentido de que, sin el cultivo moral ni la civilización, conduce finalmente a una vida insegura y peligrosa para todos o casi todos. Por eso, el cultivo de sí mismo conduce a una personalidad que tiene un alto valor y que hay que respetar adecuadamente. De hecho existen casos en los que dicho cultivo no está bien visto. Así, un consejero político, fielmente crítico y consciente de la humanidad, que crítica a un gobernante inhumano puede ser asesinado. En cambio, los seres humanos que se comportan de una manera inhumana y que les falta una cultura básica y moral, no tienen un derecho ilimitado a que se les respete la dignidad, según el libro Xunzi (que sigue en este punto a Menzius). Hay que exhortarles y enseñarles, e intentar corregirlos en una forma humana 
según las posibilidades. En caso extremo, no se excluyen, sin embargo, castigos crueles.

El principio de reciprocidad (formulado frecuentemente como una regla de oro), un principio moderado de castigo y la constatación fundada en la experiencia de que sin sanciones que afecten la dignidad humana no es posible alcanzar y garantizar una forma de vida duradera, humana y satisfactoria para todos, llevan, según el libro Xunzi, a la concepción de un concepto de dignidad humana justificado empíricamente, consistente y realista. Este concepto representaría una alternativa discutible frente a los conceptos teológicos y jusnaturalistas de la dignidad inalienable. No es acaso superfluo subrayar que el concepto filosófico de Xunzi no represente ningún impedimento para un acuerdo convencional —pragmático sobre un concepto jurídico institucionalizado de la dignidad inalienable.

Finalmente una palabra sobre el así llamado derecho humano a la identidad cultural. Desde mi punto de vista tiene poco sentido presentar un concepto semejante. Filosóficamente, el respeto a la identidad cultural debería ser una función del respeto a la dignidad humana y/o al derecho a la vida. Esto se ve muy claramente cuando se piensa en casos en los que la destrucción del espacio de vida tradicional lleva a la desaparición de sus habitantes, o cuando a alguien que sólo conoce su lengua materna, se le prohibe que hable. Junto a este hay numerosos argumentos que muestran que conceptos de identidad cultural apenas si son utilizables cuando se trata de cuestiones relevantes en los Derechos Humanos.

1. Estos conceptos no pueden ser precisados de una manera tal como fuera necesario en un contexto semejante, para poder emplearlos argumentativamente de manera aceptable, a no ser que se les relacione con fundamentalismos intolerantes e intolerables.

2. De la mera existencia de una identidad cultural no se sigue que deba seguir existiendo.

3. Las tradiciones son heterogéneas en sí. Esto vale sobre todo para aquellas tradiciones que existen desde hace mucho tiempo y que incluyen grandes espacios. Por eso es prácticamente imposible preferir una de estas tradiciones parciales frente a otra, sin tener que echar mano de estandartes extratradicionales.

4. También pertenecen a la tradición ciertas desviaciones o discrepancias frente a tradiciones anteriores

5. Las culturas son procesos abiertos a transformaciones.

6. Todas las tradiciones deben de contener momentos (y argumentos) críticos. Por ejemplo, todas las teorías filosóficas interesantes que conozco en la historia de China son críticas frente a su tradición. 
En resumen: Ni el recurso a las filosofías chinas ni una discusión de éstas nos dan argumentos para la convicción de que los valores de sistemas fundamentales, abiertos a la argumentación racional, sean funciones de una cultura específica.

\section{Posibilidades y problemas del trabajo por los Derechos Humanos}

En el marco del decenio de la educación para los Derechos Humanos (Derechos Humanos), y en el año del $50^{\circ}$ aniversario de la Declaración Universal de los Derechos Humanos, sin olvidar la preparación del jubileo del 2000, parece normal la existencia de un instituto cuya función es la enseñanza e investigación de las estrategias de educación para los Derechos Humanos: El IDHL Y lo hará de una manera empírica, partiendo de una experiencia realizada en Benin. Esta experiencia ha durado varios años. Se ha realizado en cooperación entre el instituto y la diócesis de Borgou, y ya está bien avanzada. Nosotros tenemos la pretensión de decir que esta experiencia es vital para África y que puede ser ensayada en otras partes, a condición de que los socios acepten las exigencias pedagógicas y el rigor intelectual que nosotros hemos puesto desde el principio, en tanto que formadores. Es por esto que el instituto está discutiendo actualmente con otros socios en Chad, Ruanda y Marruecos para desarrollar la misma estratégica de formación. Señalaremos, sin embargo, que no hemos hecho obra innovadora en la materia. La ClJ y otras asociaciones de defensa de los Derechos Humanos han practicado ya esta técnica para la formación parajurídica, tan adaptada a las realidades del tercer mundo. En un primer momento, explicitaremos los argumentos que llevan a comprometerse en la formación parajurídica. Después, en un segundo momento, desarrollaremos las grandes líneas de nuestro trabajo en Benin, a fin de establecer una relectura.

\section{1. ¿Por qué formar trabajadores parajurídicos?}

¿Por qué el mundo necesita más que nunca de los Derechos Humanos y por qué, para hablar de los Derechos Humanos se necesita gente preparada en este trabajo? África, Asia y América Latina sufren un inmenso déficit democrático y deformación política y económica contra la que tenemos que movilizarnos. Se trata de un trabajo considerable. El deseo de la enseñanza para los Derechos Humanos es una ocasión importante para tomar conciencia de la amplitud del trabajo que hay que llevar a cabo.

\subsubsection{Objetivos de la formación de trabajadores parajurídicos}

Los objetivos que inculcamos a los trabajadores parajurídicos que formamos son cuatro: 
a) Participar en el proceso de liberación del hombre y de la mujer.

b) Participar en el proceso de establecimiento de las condiciones de justicia.

c) Ayudar a cada mujer y a cada hombre a ser protagonistas.

d) Favorecer la emergencia de una nueva cultura política, asociando a la idea de "poder político" la del "servicio". Feliz el servidor.

Detengámonos en los dos primeros puntos.

\section{a) Ayudar a la mujer y al hombre a liberarse.}

Aquí tocamos un punto sensible porque este objetivo es dependiente de la visión que nosotros tengamos de la cultura diferente de la nuestra. En nombre de la tolerancia e incluso de un cierto complejo "occidental", ciertamente comprensible, no osamos hablar mal de sistemas que alienan la libertad individual y que hacen del grupo el sujeto del derecho (reduciéndose el individuo a un objeto de derecho: Es el caso, p.e., de la mujer en la sociedad africana tradicional).

No se trata de confundir ciertos valores que habría que conservar, y el principio mismo de la organización social que mantiene al individuo en un régimen de miedo. El miedo paraliza, aliena... Como decían los obispos de Benin, en carta pastoral del 11 de febrero de 1995: “Todo el mundo tiene miedo de todo el mundo. Este miedo es responsable de un inmovilismo social en sustancia endémica."

El inmovilismo del que hablan los obispos del Benin se inscribe dentro del déficit democrático citado antes. Es una causa de este déficit. Convencer al hombre y a la mujer de que han nacido para ser libres, significa crear las condiciones de un desarrollo real y armonioso. Este llamado a la libertad es tanto más fácil para los otros cristianos cuanto se inscribe en el mensaje evangélico. Dios hace de nosotros en Jesús hombres libres.

\section{b) Crear las condiciones de la justicia.}

Para poder vivir en seguridad y confianza el hombre necesita de la justicia. La justicia depende de la regla del derecho puesta anteriormente. Debe ser la misma para todos. Justicia va junta con igualdad de trato y equidad.

La justicia es mucho más que un objetivo a alcanzar. Es una virtud que hay que practicar siempre. Se opone a la arbitrariedad. La justicia debe ser practicada en todas las esferas de la vida económica y social: 
— En la familia

- En las comunidades aldeanas

- En la comunidad eclesial

- En el nivel del Estado

Hay que trabajar, pues, en distintos frentes:

- Enseñar al individuo que es titular de derechos, pero que tiene obligaciones frente a los otros que viven en las diferentes esferas que él frecuenta.

- Enseñar al individuo a hacer respetar sus derechos, no de manera arbitraria sino reclamando que se haga justicia. Enseñarle a conocer el aparato judicial y a confiar en la justicia.

- Exigir del juez que cumple con su trabajo

- Luchar contra todas las formas de injusticia que paralicen la vida social y que terrorizen las poblaciones (corrupción, nepotismo, etc.)

- Crear las condiciones de un rechazo de prácticas que son, por definición, antidemocráticas.

El colaborador parajurídico puede, de esta manera, convertirse en un vigilante: aquel que vigila, y que hace vigilar.

Hace falta ampliar este servicio. Hasta que el estado de derecho no haya llegado a la más pequeña del continente africano, hasta que el último campesino no conozca sus derechos, el trabajador parajurídico deberá trabajar sin descanso. Deberá educar para la justicia. Este es un servicio que se hace en vistas del objetivo del desarrollo. El colaborador parajurídico hace este servicio. En cuanto tal es un agente de desarrollo. Ya hay numerosos trabajadores parajurídicos cumpliendo su labor en el mundo, especialmente en América Latina y en Asia. 